\title{
PEMANFAATAN MULTIMEDIA SEBAGAI MEDIA PENYULUHAN KESEHATAN GIGI
}

\author{
Hestieyonini Hadnyanawati \\ Bagian Ilmu Kesehatan Gigi Masyarakat dan Pencegahan \\ Fakultas Kedokteran Gigi Universitas Jember
}

\begin{abstract}
The effort of suppression promotion and preventive as practice principle of " paradigma sehat " are concept which announcement by Departemen Kesehatan Republik Indonesia in framework reach Indonesia Sehat 2010 .This Effort as well as possible to get done by everyone Indonesia peoples, with the holistic through way dental education .For this application dental education needed medium. Multimedia are application various medium which different for associate and serve information in form text, audio, chart, animation, and video. Multimedia find occupy somebody for keep $90 \%$ what that he read, hear, see, mention and done. Using multimedia as dental education medium can be use CD / VCD multimedia module, multimedia presentation, and multimedia web .With this remainder, so using multimedia technology find service as alternative medium for public dental education
\end{abstract}

Key words: multimedia; medium education; and dental health education

\section{Pendahuluan}

Penekanan upaya promotif dan preventif sebagai penerapan prinsip " paradigma sehat" merupakan konsep yang dicanangkan oleh Departemen Kesehatan Republik Indonesia dalam rangka mencapai Indonesia Sehat tahun 2010. ${ }^{1}$ Upaya ini seyogyanya dapat diterapkan oleh setiap penduduk Indonesia secara holistik melalui penyuluhan kesehatan khususnya kesehatan gigi.

Penyuluhan kesehatan gigi dan mulut adalah suatu upaya atau kegiatan untuk menyampaikan pesan mengenai kesehatan gigi kepada masyarakat, kelompok, atau individu, dengan harapan mereka dapat memperoleh pengetahuan kesehatan gigi yang lebih baik. Harapannya dengan pengetahuan tersebut dapat mempengaruhi perubahan perilaku mereka. $^{2}$

Pada hakekatnya kegiatan dalam penyuluhan adalah suatu proses komunikasi, yaitu proses penyampaian pesan dari penyuluh kepada peserta penyuluhan. Melalui proses komunikasi, pesan atau informasi dapat diserap oleh peserta. Agar tidak terjadi kesesatan dalam proses komunikasi perlu digunakan sarana yang dapat membantu proses komunikasi yang disebut media.

Media merupakan alat atau sarana yang digunakan untuk menyampaikan pesan kepada sasaran atau orang yang dituju. Media ini dapat melalui media massa atau media antar pribadi. Media 
massa, misalnya surat kabar, majalah, radio dan televisi. Media antar pribadi misalnya pembicaraan langsung atau tatap muka, pembicaraan lewat telepon atau surat. ${ }^{3}$

Media lain yang bisa digunakan sebagai alternatif dalam penyampaian pesan adalah internet, karena teknologi internet sudah dikenal dan dipakai oleh banyak orang. Hal ini dibuktikan dengan semakin meningkatnya jumlah pengguna internet yang mengakses internet baik menggunakan komputer pribadi maupun warung internet (Warnet). ${ }^{4}$

Perkembangan teknologi internet diiringi dengan perkembangan multimedia, kedua teknologi tersebut mampu memberikan kesan yang besar dalam bidang komunikasi dan pendidikan, karena multimedia bisa mengintegrasikan teks, grafik, animasi, audio, dan video. Multimedia telah mengembangkan proses pengajaran dan pembelajaran ke arah yang lebih dinamis dan efektif. Dengan kondisi tersebut, maka multimedia dapat dimanfaatkan sebagai media alternatif untuk penyuluhan kesehatan gigi bagi masyarakat.

\section{Tinjauan Pustaka}

\section{Penyuluhan kesehatan gigi dan mulut}

Penyuluhan kesehatan gigi adalah suatu proses peyampaian pesan atau informasi mengenai kesehatan gigi kepada masyarakat, kelompok, atau individu. Dalam penyuluhan terjadi proses komunikasi antara sumber informasi (penyuluh ) dengan penerima informasi ( audien ). ${ }^{5}$

Dalam proses komunikasi, diperlukan empat komponen yang harus ada, yaitu sumber informasi, informasi, penerima informasi, dan media. Jika salah satu dari keempat komponen tersebut tidak ada, maka proses komunikasi tidak mungkin terjadi. Media atau perantara adalah apa saja yang dapat menyalurkan informasi dari sumber informasi kepada penerima informasi. $^{5}$

Secara umum, media dalam proses penyuluhan adalah sarana untuk memperlancar interaksi antar penyuluh dan pendengar ( audiens ). Sarana tersebut dapat berupa perangkat keras maupun perangkat lunak .

\section{Media Penyuluhan}

Media adalah sebuah alat yang mempunyai fungsi menyampaikan pesan. Media pembelajaran atau penyuluhan adalah sebuah alat yang berfungsi untuk menyampaikan pesan pembelajaran atau penyuluhan. Pembelajaran adalah sebuah proses komunikasi antara pembelajar, pengajar dan bahan ajar. Komunikasi tidak akan berjalan tanpa bantuan sarana penyampai pesan atau media. ${ }^{6}$

Media merupakan bentuk umum dari komunikasi yang biasanya berkaitan dengan cara apa yang mewakili penyampaian pengetahuan. Sedangkan alat dalam menyampaikan format presentasinya disebut dengan teknologi.

Peranan dan fungsi media sangat dipengaruhi oleh ruang, waktu, pendengar, serta sarana dan prasarana yang tersedia, di samping sifat dari media tersebut. ${ }^{7}$ Pemilihan media penyuluhan yang tepat didukung oleh kemampuan tenaga kesehatan ${ }^{4}$ Pada dasarnya ada 3 media penyuluhan yaitu. $^{8}$

1. Media Visual yang berguna dalam membantu menstimulasi indra mata (penglihatan pada waktu terjadinya proses pendidikan ), misalnya : slide, film.

2. Media Audio alat yang digunakan untuk menstimulasi indra pendengaran pada waktu proses penyampaian pesan, misalnya : radio, pita suara, dan piringan hitam.

3. Media Audio Visual, seperti televisi dan video cassete.

Media dan teknologi yang digunakan dalam dunia pendidikan berkembang seiring dengan perkembangan dan kemajuan teknologi. Penggunaan media penyuluhan yang baik harus memenuhi beberapa syarat, yakni :

1. Dapat meningkatkan motivasi audien.

2. Merangsang audien untuk dapat mengingat apa yang sudah dipelajari.

3. Media yang baik juga akan mengaktifkan audien dalam memberikan tanggapan dan umpan balik.

4. Dapat mendorong audien untuk melakukan praktek-praktek pemeliharaan kesehatan gigi dengan benar.

\section{Multimedia} ahli adalah :

Beberapa definisi multimedia menurut para

1. Menurut Walter Oleksy ${ }^{9}$, multimedia adalah teknologi perangkat keras (hardware) dan perangkat lunak (software) yang dapat digunakan untuk menggabungkan teks, gambar, bunyi, suara, animasi dan video pada sebuah komputer.

2. Multimedia adalah kombinasi dari teks, foto, seni grafis, suara, animasi, dan elemen-elemen video yang dimanipulasi secara digital. ${ }^{10}$ 
Dengan definisi di atas, maka multimedia dapat diartikan sebagai penggunaan beberapa media yang berbeda untuk menggabungkan dan menyampaikan informasi dalam bentuk teks, audio, grafik, animasi, dan video.

Multimedia dapat digunakan dalam; ${ }^{12}$

1. Bisnis, aplikasi bisnis untuk multimedia meliputi presentasi, pelatihan, pemasaran, periklanan, demo produk, database, katalog, pesan kilat, komunikasi jaringan.

2. Di dunia pendidikan, aplikasi multimedia dapat dipakai untuk penyampaian bahan pengajaran secara interaktif dan dapat mempermudah pembelajaran karena didukung oleh berbagai aspek: suara, video, animasi, teks, dan grafik.

3. Di rumah, aplikasi multimedia dapat dinikmati di rumah melalui komputer yang dilengkapi driver CD ROM, DVD atau player yang dihubungkan dengan televisi, seperti sega, Nintendo, atau mesin bermain.

4. Di tempat umum, penggunaan multimedia seperti di hotel, stasiun kereta api, terminal, mall pembelanjaan dan tempat umum lainnya digunakan sebagai media informasi

Secara keseluruhan, multimedia terdiri dari tiga level yaitu: ${ }^{11}$

1. Level teknis, yaitu multimedia berkaitan dengan alat-alat teknis

2. Level semiotik, yaitu representasi hasil multimedia seperti teks, gambar, grafik, dan tabel.

3. Level sensorik, yaitu yang berkaitan dengan saluran sensorik yang berfungsi untuk menerima tanda (signs).

\section{Pemanfaatan Multimedia sebagai media penyuluhan Kesehatan gigi}

Pada hakekatnya dalam penyuluhan kesehatan gigi terjadi proses pembelajaran, Dalam pembelajaran tersebut diperlukan adanya penyuluh, pendengar, materi dan media penyuluhan.

Dengan berkembangnya teknologi informasi telah memungkinkan penyimpanan serta pendayagunaan informasi dan materi penyuluhan yang lebih menarik, interaktif, mudah dipahami melalui visualisasi multimedia yang meliputi teks, citra, suara, video, dan animasi atau film. Penyajian penyuluhan dalam bentuk multimedia ini telah mengubah paradigma belajar dari hanya melihat dan membaca menjadi paradigma belajar dengan membaca, melihat, mendengar, mengamati, dan mengerjakan ( learning by seeing, reading, hearing, observing, and doing ).
Menurut Ismail (2002) ${ }^{12}$ daya ingat seseorang dapat menyimpan hanya:

- $20 \%$ dari apa yang mereka baca

- 30\% dari apa yang mereka dengar

- $40 \%$ dari apa yang mereka lihat

- $50 \%$ dari apa yang mereka sebut

$-60 \%$ dari apa yang mereka buat

- $90 \%$ dari apa yang mereka baca, dengar, lihat, sebut dan buat secara bersamaan.

Penggunaan multimedia dapat memenuhi seseorang untuk menyimpan $90 \%$ apa yang dia baca, dengar, lihat, sebut dan buat. Hal ini dikarenakan multimedia mempunyai elemen-elemen teks, grafik, video, audio dan animasi yang dapat ditampilkan secara bersamaan.

Dengan penggunaan multimedia untuk penyuluhan kesehatan gigi diharapkan pesan yang disampaikan dapat diingat semaksimal mungkin, sehingga dapat mempengaruhi perilaku sehat pendengar.

Dalam pemanfaatan multimedia sebagai media penyuluhan, materi yang akan disampaikan dapat dikemas dalam bentuk:

1. CD Modul Multimedia

yaitu modul penyuluhan kesehatan gigi yang berbasis multimedia dengan menggabungkan dan mensinergikan semua media yang terdiri dari teks, grafis, photo, video, animasi, musik dan interaktivitas yang diprogram berdasarkan teori pembelajaran.

\section{VCD Modul Multimedia}

yaitu modul penyuluhan kesehatan gigi yang berbasis multimedia yang diformat dalam dengan media VCD. Penggunaan VCD (Video Compact Disc) sebagai alternatif pemilihan media penyuluhan cukup mudah untuk dilaksanakan. Hal ini dikarenakan penggunaan media pembelajaran yang berbentuk VCD bukan merupakan hal yang baru lagi. Penggunaan media berbentuk VCD memungkinkan digunakan karena VCD player sekarang ini sudah bukan merupakan barang mewah lagi

3. Presentasi Multimedia

yaitu penyajian penyuluhan melalui presentasi materi yang disampaikan berupa teks, foto, animasi dan video yang dapat mengarahkan pendengar akan pesan yang akan disampaikan .

4. Web Multimedia

Dengan perkembangan teknologi web (jaringan Internet, ekstranet, dan Intranet) maka dokumen atau materi penyuluhan multimedia dapat diletakkan pada beberapa situs di web, sehingga dapat digunakan oleh komunitas yang lebih luas dan tidak dibatasi dengan lokasi geografis. 
Pemanfaatan multimedia sebagai media penyuluhan kesehatan gigi mempunyai keuntungan lebih efektif dan efisien dalam menyampaikan informasi. Mamun demikian juga mempunyai kekurangan yakni: dibutuhkan dana yang besar, dibutuhkan adanya ketersediaan piranti lunak dan keras komputer, keterbatasan pengetahuan tehnis dan teoris dalam pemakaiannya.

\section{Kesimpulan}

Multimedia adalah penggunaan beberapa media yang berbeda untuk menggabungkan dan menyampaikan informasi dalam bentuk text, audio, grafik, animasi, dan video. Dengan teknologi multimedia ini, dapat dimanfaatkan untuk media penyuluhan kesehatan gigi. Diharapkan dengan teknologi tersebut penyampaian materi kesehatan gigi dan mulut dapat dengan mudah diterima oleh pendengar. Karena penggunaan Multimedia dapat memenuhi seseorang untuk menyimpan $90 \%$ apa yang dia baca, dengar, lihat, sebut dan buat.

Pemanfaatan multimedia sebagai media penyuluhan kesehatan gigi bisa berupa CD / VCD modul multimedia, presentasi multimedia, dan web multimedia. Keuntungan dengan pemakaian multimedia adalah lebih efektif dan efisien dalam menyampaikan informasi. Mamun demikian juga mempunyai kekurangan yakni: dibutuhkan dana yang besar, dibutuhkan adanya ketersediaan piranti lunak dan keras komputer, keterbatasan pengetahuan teknis dan teoris dalam pemakaiannya.

\section{Daftar Acuan}

1. Departemen Kesehatan RI, Upaya Kesehatan Gigi Masyarakat, Jakarta, Depkes RI. 1999.

2. Notoatmodjo, S. Pengantar Pendidikan dan Ilmu Perilaku Kesehatan. Andi Offset. ogyakarta. 1993.

3. Herjulianti, E., Indriani, T.S., dan Artini. Pendidikan kesehatan Gigi. ECG. Jakarta. 2002.

4. Hadnyanawati, H. Pemanfaatan teknologi internet sebagai media alternatif dalam penyampaian penyuluhan kesehatan gigi kepada masyarakat. Jurnal kedokteran Gigi. FKG Unpad. Bandung. 2003; 15(1): 178-82.

5. Prastati, T., Irawan, P., Media sederhana. Direktorat Jendreral Pendidikan Tinggi. Departemen Pendidikan Nasional. 2001: 3-11.

6. Bovee, Courland. Business Communication Today. Prentice Hall. New York. 1997.

7. Ahmad R. Media Instruksional Edukatif. Rineka Cipta. Jakarta.1997.

8. Astoeti, T.E. Total Quality Management dalam Pendidikan Kesehatan Gigi di sekolah. Jakarta. RajaGrafindo Persada. 2006.

9. Walter Oleksy. The Information Revolution: Education \& Learning, Multimedia. 1995.

10. Vaughan Tay. Multimedia : Making It Work. McGraw-Hill Companies,Inc. sixth edition. 2004.

11. Mayer, R. Multimedia Learning. USA: Cambride University Press. 2001.

12. Zain Ismail. Aplikasi Multimedia Dalam Pengajaran. Utusan Publications \& Distributor Sdn. Bhd. 2002. 